January 2016

\title{
Modeling at farm level: Positive Multi-Attribute Utility Programming
}

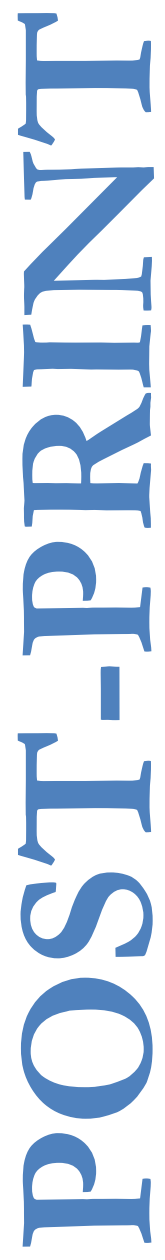

Gómez-Limón, José A.

Gutiérrez-Martín, Carlos

Riesgo, Laura

Paper accepted to be published in Omega. The International Journal of Management Science

Editorial: Elsevier Science ISSN: 0305-0483 http://dx.doi.org/10.1016/j.omega.2015.12.004

This research is co-financed by the Spanish Ministry of Economics and Competitiveness (MINECO) and the European

Regional Development Fund (ERDF) through the project MERCAGUA (AGL2013-48080-C2-1-R). 


\title{
Modeling at farm level: Positive Multi-Attribute Utility Programming
}

\author{
José A. Gómez-Limón a , Carlos Gutiérrez-Martín ${ }^{\mathrm{b}}$, Laura Riesgo c,* \\ ${ }^{\text {a }}$ Department of Agricultural Economics, Faculty of Law and Business Sciences, University of Cordoba, Puerta \\ Nueva s/n, E-14071 Córdoba, Spain \\ ${ }^{\mathrm{b}}$ Department of Agricultural Economics, School of Agricultural Engineering, University of Cordoba, Campus \\ Rabanales (Edif. Gregor Mendel, C-5), Carretera N-IV km. 596, E-14014 Córdoba, Spain \\ ${ }^{\mathrm{c}}$ Department of Economics, University Pablo de Olavide, Ctra. de Utrera, km.1, E-41013 Seville, Spain
}

\begin{abstract}
This article proposes a new mathematical programming model for the simulation of farmers' decision-making. We have developed a model based on a multi-attribute utility approach that takes into consideration the most relevant attributes of farmers within a positive framework. This approach overcomes the limitations found in some mathematical models used in the literature to simulate farmers' behavior. A five-step procedure is presented in order to elicit the utility function that reproduces farmers' current decision-making. We illustrate this positive multi-attribute approach using a sample of farmers in an irrigated area in southern Spain, where our simulations demonstrate the accurateness of the model in reproducing actual farmers' decision-making. We also find evidence that the model is able to explain the heterogeneous behavior of farmers within a homogeneous agricultural system.
\end{abstract}

Key words: Decision making, Farmers’ behavior, Multicriteria, Mathematical programming, Simulation, Positive approach.

\footnotetext{
${ }^{*}$ Corresponding author. Tel.: +34 9543498 51; fax: +34 9543493 39. E-mail addresses: jglimon@uco.es (J.A. Gómez-Limón), es1gumac@uco.es (C. Gutiérrez-Martín), laurariesgo@upo.es (L. Riesgo)
} 


\section{Modeling at farm level: Positive Multi-Attribute Utility Programming}

\section{Introduction and objective}

Ex-ante policy impact assessment usually depends on the reaction of the farmers affected by the policy instruments implemented. Mathematical programming (MP) models have been widely applied to simulate their behavior, usually under the assumption that farmers behave "rationally" as profit maximizers, i.e., their decision-making is led by a utility function $U$ equivalent to profit $(U=\pi)$. Traditionally, the parameters of the objective function and the constraints were not calibrated to observed data and, as a consequence, these MP models did not guarantee a perfect reproduction of farmers' observed behavior. This has led some authors to label these models as normative mathematical programming (NMP) models [1, 2]. In addition to this inability to reproduce observed behavior, another disadvantage of the NMP models is the discontinuity of the simulations provided (i.e., a switch from one corner-point solution to another when some variables are modified).

Differences between simulations using NMP models and decision-makers' (farmers) observed behavior have encouraged authors to develop a more general theoretical framework to model and predict farmers' behavior. A first attempt to cope with the limitations of such models was to include uncertainty and farmers' risk preferences into the analysis. This was introduced by the Expected Utility Theory (EUT) developed by von Neumann and Morgenstern [3], where profit is considered a stochastic rather than a deterministic variable. The EUT assumes the existence of a utility function $U$, which has profit as the unique argument $(U(\pi))$, and also that decision-makers try to maximize its expected value. In fact, EUT has become one of the most popular approaches to simulate farmers' decision-making, and is implemented through several mathematical programming tools [4]. The EUT can be considered as a first step toward broadening the profit maximizer assumption, including higher moments of the expected profit and incorporating observed attitudes of farmers toward risk. However, differences between observed and simulated behavior through EUT approaches have led to criticism of EUT, and consequently alternative non-EUT approaches have recently been developed (for a review see [5], and for applications in agriculture see [6]). Nevertheless, EUT is currently the dominant theory concerning choice under risk in applied economic research [7]. 
In late 1980s the emergence of Positive Mathematical Programming (PMP) brought an appealing breath of positivism to MP, as adjustments of the parameters of the model allowed the reproduction of farmers' behavior in a given reference situation or base year. This approach, formalized by Howitt [8], calibrates a non-linear profit objective function on the basis of the observed behavior of farmers (i.e., observed crop mix) to exactly reproduce their behavior. Another advantage of the PMP is that it provides more flexible and realistic simulation responses than NMP models (i.e., it avoids unlikely abrupt discontinuities in simulated behavior) [9]. Moreover, more recent developments [10,11] has extended PMP approach to include risk preferences in the analysis, calibrating mean-variance $(\mathrm{E}-\mathrm{V})$ farm models under the assumption of EUT maximization. This positive approach has renewed interest in MP modeling for assessing the ex-ante impacts of agricultural and environmental policies. In fact, since its introduction, PMP and related methods have been applied to a rapidly growing number of models at farm, regional, and sectorial level. For a review of this literature see Nakashima [12] and Heckelei et al. [13].

Despite the PMP and the EUT are based on the assumption that farmer's behavior can be modeled by maximizing profits or any utility function with profits as a single attribute, since the 1970s, real-life observations have refuted this simplification (e.g., [14-18]). These authors argued that farmers' decision-making processes are driven by various -usually conflictingcriteria, related to their economic, social, cultural, and natural environment situation, in addition to the expected profit (or its higher moments). Recent empirical studies (e.g., [19-23]) confirm this evidence.

The Theory of Planned Behavior (TPB) provides a comprehensive assessment of the relevant attributes guiding the decision-making process [24]. According to the TPB, individuals' behavior derives from their intentions, which are also based on their beliefs. Three types of beliefs can be distinguished: (i) attitudes or behavioral beliefs, related to the outcomes of the behavior and the evaluations of these outcomes, producing favorable or unfavorable attitudes toward the behavior; (ii) norms or normative beliefs, related to the normative expectations of others and the motivation to comply with these expectations, resulting in perceived social pressure or subjective norms, and (iii) control beliefs or perceived behavioral control, related to the presence of factors that may facilitate or impede performance of the behavior and the perceived power of these factors.

The TPB has been widely implemented to analyze farmers' behavior in various real situations [25]. Most of these studies (e.g., [26-30]) show that farmers' attitudes toward their 
behavior explain a great deal of the variance in intentions, and thus are the major determinants of farmers’ strategic and entrepreneurial behavior.

Therefore, attitudes can be seen as a summary of psychological evaluations based on the individual's beliefs about the "goodness” or “badness” of an object, normally associated with a particular attribute [31]. The implication of the TPB is clear: modeling farmers' decisionmaking processes (building models capable of simulating farmers' behavior) requires the consideration of more than one attribute. Hence, it can be assumed that producers' beliefs concerning the attributes will govern their decision-making towards maximizing a multiattribute utility function (MAUF, $U\left(\pi, a_{1}, \ldots, a_{n}\right)$ ), where all attitudes/attributes considered are condensed [27, 29, 30, 32]. This is the main idea underlying Multi-Attribute Utility Theory (MAUT), an approach largely developed after the publication of the seminal work by Keeney and Raiffa [33] to overcome the limitations of the single-attribute utility function.

The objective of this article is to develop a new mathematical programming approach at farm level based on both the MAUT framework (i.e., considering a MAUF capable of including the most relevant farmers' criteria) and a positive approach (i.e., a 'calibrated' method to accurately reproduce farmers' actual decision-making). This new approach also provides a new tool for ex-ante assessment since it will allow simulating farmers' decision-making at present but also when facing any hypothetical future scenario, such as any agricultural policy reform or market change.

In order to achieve this objective the document is organized as follows. After this introduction, the next section critically reviews existing methods to estimate farmer's MAUFs and explains the differences observed between simulated and actual behavior. The third section introduces the positive method we propose to simulate farmers' behavior under the MAUT paradigm, aiming to overcome the limitations found in previously developed approaches. The fourth section demonstrates an empirical application of the proposed method and illustrates the main results obtained, and the last section concludes.

\section{Multi-Attribute Utility Functions: a literature review}

Farmers' decision-making is mainly focused on the selection of those crop-mixes that allow the maximization of their utility function subject to a set of constraints. The multi-attribute utility function $(U)$ depends on the attributes the farmer is concerned with, such as profit, risk, etc. The values of the attributes also depend on the crop mixes selected by the farmer (decision 
variables) and the limitations (constraints) established by resources availability (land use, labor, machinery, water, etc.), technical requirements (agronomic and soil and weather conditions) and legal or policy requirements (e.g., production quotas).

Modeling farmers' behavior requires the definition of these three elements: decision variables $\left(\vec{x}_{c}=\left(x_{1}, \ldots, x_{c}, \ldots, x_{n}\right)\right)$, attributes $\left(f_{i}\left(\vec{x}_{c}\right)\right)$ and constraints $\left(A \vec{x}_{c} \leq B\right)^{1}$. Thus, the decision-making problem a farmer faces at the beginning of each cropping year can be represented as the following:

$\operatorname{Max} U\left(\vec{x}_{c}\right)=U\left(u_{1}\left(f_{1}\left(\vec{x}_{c}\right)\right), \ldots, u_{i}\left(f_{i}\left(\vec{x}_{c}\right)\right), \ldots, u_{m}\left(f_{m}\left(\vec{x}_{c}\right)\right)\right)$

s.t.: $\quad A \vec{x}_{c} \leq B$

where $u_{i}\left(f_{i}\left(\vec{x}_{c}\right)\right)$ is the single-attribute or partial utility function related to attribute $i$.

By solving the problem (1) farmers determine their decision variables (i.e., farm area cultivated with each crop, $\left.\vec{x}_{c}\right)$, which can be observed ex-post $\left(\vec{x}_{c}^{o b s}\right)$. If an analyst aims to accurately simulate farmers' behavior, the observed decision variables must be considered as the optimal solution for the problem (1), i.e., the observed decision variables must be the solution of maximizing the utility function considering the efficient set defined by the constraints. Therefore a positive approach requires the analyst to elicit the expression of the efficient set and the functional form of the MAUF to be consistent with the observed decision variables.

We next review associated literature to critically revisit previous studies focused on the positive assessment of the MAUF, highlighting elements to be addressed in order to build a sounder model.

\subsection{Dealing with 'inefficient' observed decision-making}

Since (i) MP models are simplifications of real complex systems (i.e., not all actual decision variables, attributes or constraints involved in farmers' decision making are included in the model due to the difficulty of their identification and/or mathematical modelization), and (ii) MP models are fed with data which is not perfectly accurate (i.e., measurement errors during data gathering), the actual efficient set cannot be perfectly assessed. As a consequence, observed decisions may be considered as "inefficient” when they do not belong to the calculated

\footnotetext{
${ }^{1}$ Despite only a set of linear constraints is considered in this article, non-linear constraints can be included in the analysis without affecting the validity of the model.
} 
efficient set. However, Paretian efficiency is a necessary condition which guarantees the rationality of any solution provided by the MAUT approach [34], and consequently any “inefficient” observed solution needs to be projected onto the efficient set. This projected point is considered the “closest” rational solution of farmers' decision-making for operational purposes.

Previous studies on the positive assessment of the MAUF projected "inefficient” observed decisions by calculating the closest efficient point belonging to a proxy of the actual efficient set [35-38], or by projecting radially the observed decisions using a Data Envelopment Analysis (DEA) approach [39]. This last approach allows the attainment of efficient projected decisions, but it does not consider the different importance given to each attribute by decision-makers when projecting observed decisions. As explained subsequently, the method developed in this article projects "inefficient” observed decisions onto the efficient set, considering the relevance of each attribute for the farmer. "Inefficient” observed decisions are projected using a sound directional projection that considers the ideal point as reference and overcoming the limitations of any misspecification of the model derived from simplification or measurement errors.

\subsection{Defining the efficient set}

The feasible set is established by the $p$ inequalities and $q$ equalities constraining the farmer's decision problem (1). Among all the points defining the feasible set, we are only interested in the efficient set, since this is where the indifference or iso-utility curve lands and consequently where decision-makers maximize their utility function.

Although calculating points belonging to the efficient set is possible using traditional methods (i.e., constraint, weighting or the multi-objective simplex methods, see [40]), the analytical expression of this set is usually unknown, especially when non-linear constraints are included in the problem. Sumpsi et al. [35], Amador et al. [36], and André et al. [38] approximated the feasible set using a hyper-plane connecting the efficient points included in the pay-off matrix (equivalent to the segment formed by the points $\mathrm{B}$ and $\mathrm{C}$ in two dimensions, see Fig. 1). This implies that any linear combination of the points of the pay-off matrix was (incorrectly) considered to belong to the efficient set, and thus would be wrongly eligible to be the “optimum” solution for eliciting farmers’ MAUF. André and Riesgo [37] developed a more accurate approximation of the efficient set by regressing a hyper-plane on the basis of a limited number of efficient points included in the compromise set, as a subset of the whole efficient set interpreted as the "landing area" for the utility curve [34, 41]. However, as the authors 
themselves noted, this approach also results in approximation errors, since the points belonging to the regressed hyper-plane may not belong to the actual efficient set. These approximation errors suggest a need to consider the actual efficient set in order to properly estimate farmers' MAUF.

An illustration of the approximation errors caused by projecting observed points onto a linear approximation of the real efficient set can be seen in Fig. 1.

\section{Case 1}

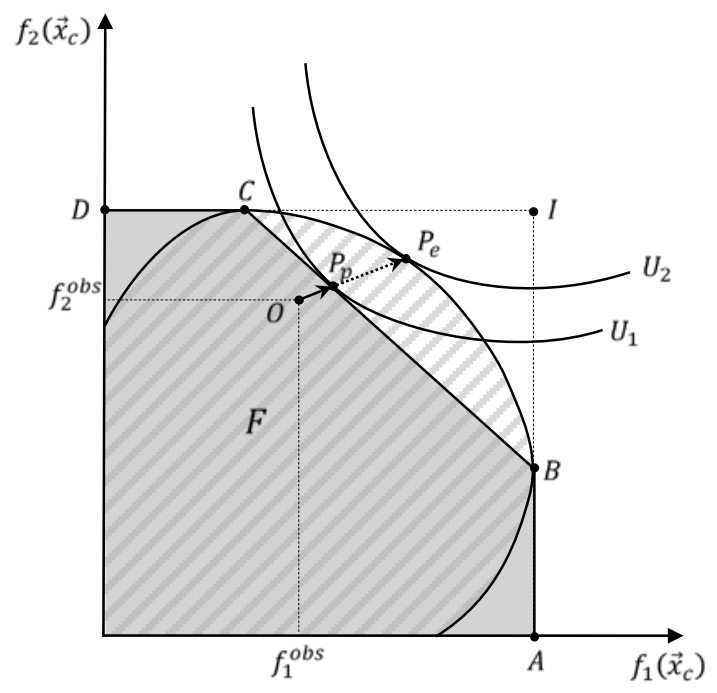

Case 2

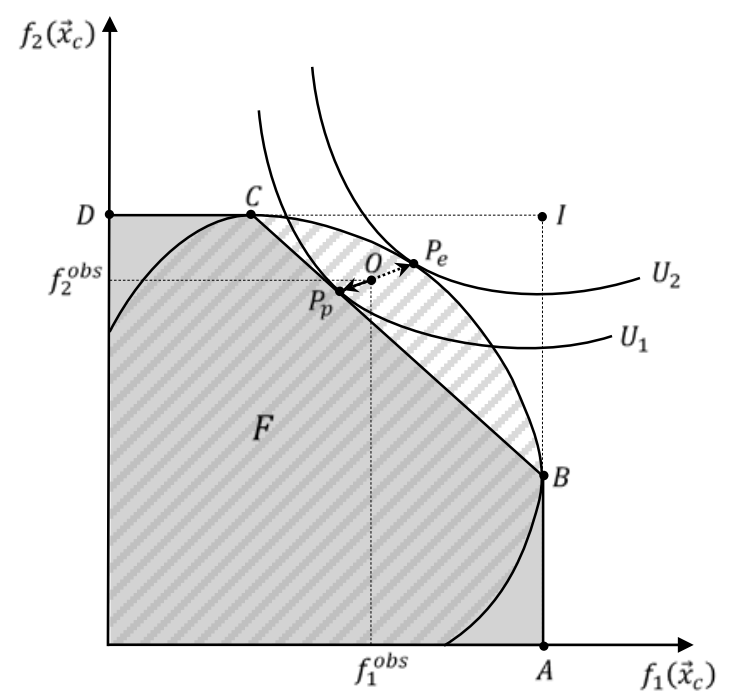

Fig.1. Potential errors caused by projecting observed points onto linear approximations of the efficient set

In the first case, the observed solution $(O)$ can be considered inefficient since it is not located on the actual efficient frontier. If this point is projected onto the linear approximation of the efficient set defined by the segment $\overline{B C}$, the resulting point is $P_{p}$. Considering this point as the "optimum" solution where the utility function is landing, the result achieved by the maximized MAUF is $U_{1}$. However, an approximation error occurred since if the projection were correctly applied onto the actual efficient set $\left(P_{e}\right)$, the resulting MAUF would be $U_{2}\left(U_{1} \neq U_{2}\right)$.

Similarly, in case 2, the observed solution $(O)$ is beyond the linear approximation of the efficient set. Projecting the observed point onto the linear approximation of the efficient set (point $P_{p}$ in segment $\overline{B C}$ ) also causes an approximation error, resulting in a biased MAUF estimation $\left(U_{1}\right)$. Calculating the utility function landing in the real projected point $P_{e}$ results in a different utility function $U_{2}\left(U_{1} \neq U_{2}\right)$. 
These approximation errors suggest the need to consider the actual efficient set to properly estimate farmers’ MAUF.

As is mentioned above, André [39] developed an approach that avoids any approximation to the efficient set, using a method that identifies points of the actual efficient set by radially expanding the single-attribute utility functions as much as possible using a DEA-based method. However, this approach assumes arbitrary weights assigned to each attribute when applying the radial expansion of the observed point. This shortcoming means that this approach is not sufficiently accurate in eliciting farmers' MAUFs in order to exactly simulate their behavior.

\subsection{Selecting the MAUF functional form and eliciting MAUF parameters}

The selection of the functional form of a MAUF should be based on both the mathematical and economic properties and the ability of such function to simulate farmers' decision-making. Due to their simplicity in terms of interpretation and elicitation, most of the existing literature has relied on the use of additive MAUFs (e.g., [42-44]). Despite the fact that additive utility function is associated with the assumption of somewhat restrictive conditions [33], this functional form may be considered as an approximation to the real utility function under certain conditions [45]. In any case, non-linear utility functions such as linear-multiplicative [37] or power functions $[39,46]$ seem to be better approximations to the real utility function.

The Positive Multi-Attribute Utility Programming (PMAUP) proposed in this article to simulate farmers' behavior aims at overcoming the weaknesses of previous studies and to develop a sound and useful approach to simulate actual producers' decision-making processes. According to this new approach, the observed solution will be projected onto the actual efficient set following a directional vector connecting observed and ideal points, taking into account the relative importance given to all criteria. Moreover, assuming farmers act rationally, the resulting efficient solution will be considered as the landing point of the farmers' MAUF. At this tangency point, the value of the slope of the efficient set (marginal rate of transformation, $\mathrm{MRT}^{2}$ ) must be equal to the value of the slope of the iso-utility curve (marginal rate of substitution, $\mathrm{MRS}^{3}$ ). Finally, assuming a MAUF shaped as a homothetic Cobb-Douglass function, the expression equaling MRT and MRS will allow the estimation of the unknown

\footnotetext{
${ }^{2}$ The marginal rate of transformation $\left(M R T_{i, j}\right)$ within the MAUT framework can be interpreted as the rate at which the achievement of one attribute $\left(f_{i}\right)$ must be sacrificed in order to reach a marginal unit of another attribute $\left(f_{j}\right)$.

${ }^{3}$ The marginal rate of substitution $\left(M R S_{i, j}\right)$ between any pair of attributes $i$ and $j\left(M R S_{i, j}\right)$ shows the rate at which a decision-maker (i.e., a farmer) is willing to renounce attribute $i$ in exchange for achieving an additional unit of attribute $j$ while maintaining the same level of utility.
} 
parameters of the utility function. This MAUF can be considered the objective function that the farmer aims at maximizing in any scenario he/she must face.

\section{Positive Multi-Attribute Utility Programming}

This section is focused on the development of the PMAUP approach proposed, explaining the five steps required to estimate the utility function that simulates farmers' behavior under the MAUT framework.

\subsection{Projecting the observed solution}

As mentioned in Section 2, farmers' decision-making is driven by the maximization of a MAUF including the $m$ attributes $f_{i}\left(\vec{x}_{c}\right)$ relevant for farm management (problem (1)). For operational purposes, we assume that (a) all relevant attributes are objectives to be maximized (i.e., more-is-better attributes) ${ }^{4}$, and (b) each single-attribute or partial utility function $\left(u_{i}\left(f_{i}\left(\vec{x}_{c}\right)\right)\right.$ is equal to the corresponding attribute ${ }^{5}\left(f_{i}\left(\vec{x}_{c}\right)\right)$ properly normalized to be bounded between 0 and 1 . Thus, the crop-mix selection $\left(\vec{x}_{c}\right)$ can be seen as a multi-objective programming (MOP) decision-making problem.

MOP problems seek to obtain the Pareto-efficient subset from the feasible solutions (election-possibility set, denoted as $F$ ), assuming that whatever preferences decision-makers may have, their choice will belong to the efficient frontier [48]. A first approximation to this efficient frontier can be assessed through the pay-off matrix. This matrix is obtained by maximizing each of the objectives separately, subject to the constraint set (see Table 1).

\footnotetext{
${ }^{4}$ Note that this assumption does not imply any loss of generality. A less-is-better attribute (objective to be minimized) can be transformed into a more-is-better attribute simply by multiplying it by -1 . If the attribute is to precisely reach a certain target (goal), this can be written as an objective minimizing the distance (or maximizing the opposite of the distance) from the attained value to the target value, so that it can be formulated as a less-isbetter (or more-is-better) objective. Therefore, the formulation proposed, which considers all attributes as objectives to be maximized, allows us to deal with any problem involving any of the relevant types of attributes (objectives or goal types) considered in the farmer's MAUF.

${ }^{5}$ This simplification assumes the use of linear single-attribute utility-indifferent curves (constant partial marginal utility), a rather strong assumption that can be regarded as a close enough approximation if the attributes vary within a narrow range [47]. There is some evidence for this hypothesis in agriculture. Huirne and Hardaker [45] have shown how the slope of the single-attribute utility function has little impact on the ranking of alternatives. Likewise, Amador et al. [36] analyzed how linear and quasi-concave functions yield almost the same results. This evidence, therefore, justifies the adoption of this simplification in the elicitation of our positive MAUF.
} 


\section{Table 1}

Pay-Off Matrix for $m$ Objectives

\begin{tabular}{lcccccc}
\hline & & Value for $f_{1}$ & Value for $f_{2}$ & $\ldots$ & Value for $f_{m}$ \\
\hline $\operatorname{Max} f_{1}\left(\vec{x}_{c}\right)$ & s.t. $\quad A \vec{x}_{c} \leq B$ & $f_{11}=\boldsymbol{f}_{1}^{*}$ & $f_{12}$ & $\ldots$ & $f_{1 m}$ \\
$\operatorname{Max} f_{2}\left(\vec{x}_{c}\right)$ & s.t. $\quad A \vec{x}_{c} \leq B$ & $f_{21}$ & $f_{22}=\boldsymbol{f}_{2}^{*}$ & $\ldots$ & $f_{2 m}$ \\
$\ldots$ & & & $\ldots$ & $\ldots$ & $\ldots$ & $\ldots$ \\
$\operatorname{Max} f_{m}\left(\vec{x}_{c}\right)$ & s.t. $\quad A \vec{x}_{c} \leq B$ & & $f_{m 1}$ & $f_{m 2}$ & $\ldots$ & $f_{m m}=\boldsymbol{f}_{m}^{*}$ \\
\hline
\end{tabular}

The elements of the main diagonal in the pay-off matrix represent the "ideal point" $(I)$. The ideal point is typically infeasible given the usual conflict among objectives. However this is a point of reference, since any rational decision-maker seeks a feasible solution as "close" as possible to this point. The method proposed in this article considers the ideal point as a reference point to project the observed solution $(O)$ onto the efficient frontier. Thus, as a first step, the “closest” efficient point $(P)$ to points $O$ and $I$ is calculated (see Fig. 2).

Projecting a point requires the introduction of a distance function in the analysis. The measure of the distance (that may be interpreted as a degree of closeness) between the points $O$ and $I$ regarding the ith attribute is defined by:

$d_{i}=\left|f_{i}^{*}-f_{i}^{o b s}\right|=\left|f_{i}^{*}-f_{i}^{P}\right|+\left|f_{i}^{P}-f_{i}^{o b s}\right|$

where $f_{i}^{*}$ is the ideal point of the attribute $i$, and $f_{i}^{o b s}$ and $f_{i}^{P}$ are the values for attribute $i$ in the observed $(O)$ and the projected point $(P)$, respectively.

The distances obtained for all the attributes can be aggregated into a composite distance function. The Minkowski's distance functions $L_{h}$ help to calculate different composite distance functions by following the general expression:

$L_{h}=\left[\sum_{i=1}^{m} w_{i}\left|f_{i}^{*}-f_{i}^{o b s}\right|^{h}\right]^{\frac{1}{h}}=\left[\sum_{i=1}^{m} w_{i}\left|f_{i}^{*}-f_{i}^{P}\right|^{h}\right]^{\frac{1}{h}}+\left[\sum_{i=1}^{m} w_{i}\left|f_{i}^{P}-f_{i}^{o b s}\right|^{h}\right]^{\frac{1}{h}}$

where $w_{i}$ is the weight assigned to each attribute $i$, showing its relative importance for the decision-maker, and $h$ is a parameter that shows the metric used to define the distance functions.

Including weights $\vec{w}=\left(w_{1}, \ldots, w_{i}, \ldots, w_{m}\right)$ in the expression for distance measurement aims to modulate the individual distances within the composite distance function according to the relative importace of the attributes for the farmer (the more important an attribute $i$, the more 
relevant the distance for that attribute $i$ within $L_{h}$ ). For operational purposes the weights are normalized to total one $\left(\sum_{i=1}^{m} w_{i}=1\right)$.

Since at the beginning of the process we do not have any knowledge on the weights given to the attibutes by the farmer, a process of $K$ iterations is proposed to estimate those values. Initially (for iteration $k=1$ ) we consider that all weights have the same importance (i.e., $w_{i}{ }^{1}=$ $1 / m$ for every $i)^{6}$.

Theoretically, there are infinite measures of distance by varying $h$. However, three metrics are identified as the most used in the literature: $h=1$ (Manhattan distance), $h=2$ (Euclidean distance) and $h=\infty$ (Chebyshev distance). We propose the use of the Euclidean distance for point projections, as is normal in economic analysis. Note that by using this metric, the closest efficient solution is the result of the intersection between the straight-line connecting $O$ and $I$ and the efficient frontier. Thus, for the Euclidean metric, the closest efficient solution to points $O$ and $I$ for the first interaction (for $k=1$, point $P^{1}$ ) can be obtained by solving the following problem:

$\operatorname{Max} \lambda$

$$
\begin{array}{lll}
\text { s.t.: } & f_{i}\left(\vec{x}_{c}\right)=f_{i}^{o b s}+\lambda w_{i}{ }^{1}\left(f_{i}^{*}-f_{i}^{o b s}\right) & \forall i \\
& & A \vec{x}_{c}-B \leq 0 \\
& w_{i}{ }^{1}=1 / m \quad \forall i &
\end{array}
$$

where the first set of constraints represents the expression of the straight-line connecting $O$ and I.

This problem allows us to obtain both the efficient values of each attribute in $P^{1}$ (i.e., $\left.\vec{f}_{i}^{1}=f_{1}^{1}, \ldots, f_{i}^{1}, \ldots, f_{m}^{1}\right)$ and the corresponding efficient crop-mix $\left(\vec{x}_{c}^{1}\right)$. By using different weights $w_{i}^{k}$ in problem (4), additional efficient points $P^{k}\left(\vec{f}_{i}^{k}\right)$ will be obtained in successive iterations.

\footnotetext{
${ }^{6}$ Any other alternative values for $w_{i}$ can be considered as a starting point for the iterative process proposed. Despite the initial values actually taken for the first iteration, results will converge into the actual ones.
} 


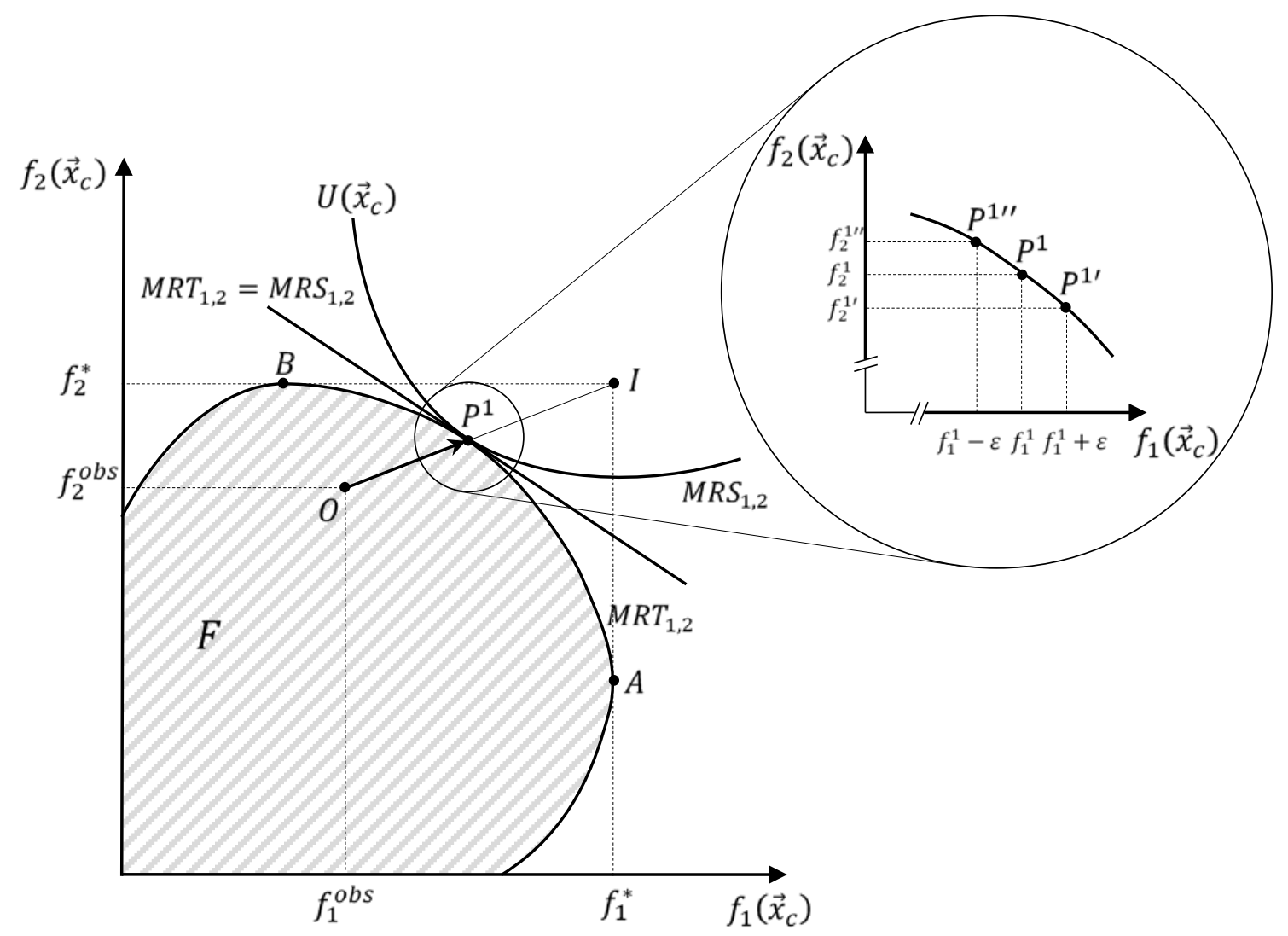

Fig. 2. Method for a MAUF with two attributes $(\boldsymbol{m}=2)$ in the first iteration $(\boldsymbol{k}=1)$

\subsection{Estimating the Marginal Rate of Transformation (MRT)}

As mentioned above, the analyst may not accurately determine the mathematical expression for the actual efficient set when dealing with MOP problems. Thus, the slope of the efficient set in the projected point $P^{k}$ (i.e., the marginal rate of transformation for any pair of attributes $i$ and $j, M R T_{i, j}$ ) needs to be calculated numerically. In order to do so, two additional efficient points close to $P^{k}$ are obtained in each iteration (denoted as $P^{k^{\prime}}$ and $P^{k^{\prime \prime}}$ ) for each pair of attributes $i$ and $j$. Points $P^{k^{\prime}}$ and $P^{k^{\prime \prime}}$ allow us to calculate the $M R T_{i, j}$ as the slope $\beta_{i, j}$ between those points ${ }^{7}$. Mathematically, these additional solutions in the $k$ th iteration are obtained by solving the following problems ${ }^{8}$ :

\footnotetext{
${ }^{7}$ Note that the estimation of the MRT is carried out using pairs of attributes ceteris paribus, i.e., it is calculated on the resulting isoquant for the two attributes considered, assuming the rest of the attribute values remain constant as in point $P^{k}$.

${ }^{8}$ It can be proved that for a sufficiently small value of $\varepsilon$ the $M R T_{i, j}^{k}$ can equally be obtained by maximizing $f_{i}$ subject to $f_{j}\left(\vec{x}_{c}\right)=f_{j}^{k} \pm \varepsilon$.
} 
s.t.: $\quad A \vec{x}_{c}-B \leq 0$

$$
\begin{aligned}
& f_{i}\left(\vec{x}_{c}\right)=f_{i}^{k}+\varepsilon \\
& f_{l}\left(\vec{x}_{c}\right)=f_{l}^{k} \quad \forall l \neq i, j
\end{aligned}
$$

s.t.: $A \vec{x}_{c}-B \leq 0$

$$
\begin{aligned}
& f_{i}\left(\vec{x}_{c}\right)=f_{i}^{k}-\varepsilon \\
& f_{l}\left(\vec{x}_{c}\right)=f_{l}^{k} \quad \forall l \neq i, j
\end{aligned}
$$

where $\varepsilon$ is a small positive number.

Results from (5) and (6), denoted as $P^{k^{\prime}}\left(f_{1}^{k}, \ldots, f_{i}^{k}+\varepsilon, \ldots f_{j}^{k^{\prime}}, \ldots f_{m}^{k}\right)$ and $P^{k^{\prime \prime}}\left(f_{1}^{k}, \ldots, f_{i}^{k}-\varepsilon, \ldots f_{j}^{k^{\prime \prime}}, \ldots f_{m}^{k}\right)$, determine the $M R T_{i, j}^{k}$ as follows:

$M R T_{i, j}^{k}=\left.\frac{\partial f_{j}}{\partial f_{i}}\right|_{P^{k}}=\beta_{i, j}^{k}=\frac{f_{j}^{k^{\prime \prime}}-f_{j}^{k^{\prime}}}{\left(f_{i}^{k}-\varepsilon\right)-\left(f_{i}^{k}+\varepsilon\right)}=\frac{f_{j}^{k^{\prime}}-f_{j}^{k^{\prime \prime}}}{2 \varepsilon}$

\subsection{Estimating the Marginal Rate of Substitution (MRS)}

Since the $M R S_{i, j}$ measures the slope of the iso-utility curve, it can also be considered as a measure of the relative importance given for the farmer to attributes $i$ and $j$ (weights $w_{i}$ and $\left.w_{j}\right)$ :

$M R S_{i, j}=\frac{d u_{i}}{d u_{j}}=-\frac{\partial U / \partial u_{j}}{\partial U / \partial u_{i}}=-\frac{w_{j}}{w_{i}}$

According to economic theory, a rational farmer chooses an efficient solution at point $P^{k}$ where the $M R S_{i, j}^{k}$ over the iso-utility curve is equal to the $M R T_{i, j}^{k}$ over the efficient frontier for every pair of attributes $i$ and $j[49,50]$. In other words, in equilibrium decisions over attributes (and corresponding crop-mixes) are such that:

$M R S_{i, j}^{k}=M R T_{i, j}^{k} \quad \forall i \neq j$

Which implies:

$\beta_{i, j}^{k}=-\frac{w_{j}^{k+1}}{w_{i}^{k+1}} \quad \forall i \neq j$

\subsection{Iterative procedure converging in actual MRT and MRS}

As is explained in Section 3.1, we propose starting the first iteration by considering $w_{i}{ }^{1}=$ $1 / m$ for every attribute in order to obtain the initial projection of the observed solution $O$ onto the efficient frontier (point $P^{1}$ ). Even if the weights of attributes were wrongly assigned in the first iteration (i.e., in (4) all attributes were assumed to be equally important for the farmer), the 
expression (10) allows us to re-estimate weights $\vec{w}$ in each iteration $k$. This requires the solution to a system of $m(m-1) / 2$ equations including one equation per each pair of attributes, and an additional normalizing equation $\sum_{i=1}^{m} w_{i}{ }^{k}=1$. Although the number of equations is larger than the number of variables $(m)$, the system yields a single feasible solution, since all equations derived from (10) are slopes of straight lines passing (infinitesimally) through the point $P^{k}$ and included within a unique hyper-plane in the $m$-dimensional attribute space. The re-estimated weights ( $\vec{w}^{k+1}$ ) are then used to project the point $O$ again onto the frontier, obtaining the point $P^{k+1}$.

Despite the values initially allocated to $\vec{w}^{1}$, it has been empirically proved that the iterative process allows convergence into unique values of $\vec{w}^{K}, M R T_{i, j}^{K}$ and $M R S_{i, j}^{K}$ that can be considered as the actual values. Iterations will be performed until the differences in the weights calculated in two successive iterations were lower than a positive small number $\delta$ :

$\left|w_{i}^{k}-w_{i}^{k+1}\right|<\delta \quad \forall i$

Therefore, actual values for $M R T_{i, j}$ and $M R S_{i, j}$ in equilibrium can be achieved through $K$ iterations, regardless the weights allocated in the first iteration.

\subsection{Eliciting farmers' MAUF}

The information provided by the equilibrium point $P^{K}$ over the efficient frontier $\left(M R T_{i, j}\right)$ allow us to integrate a MAUF landing on the projected decision (proxy of the observed point) as the optimal decision given the existing constraints, whatever the mathematical functional form for the utility function.

Taking into account the pros and cons of alternative MAUF specification forms, we propose to use the homothetic Cobb-Douglas specification [51] as a reasonable approximation to a real farmer's utility function [52]:

$U\left(u_{1}, \ldots, u_{m}\right)=\prod_{i=1}^{m}\left[u_{i}\left(f_{i}\right)\right]^{\alpha_{i}}$

where $\sum_{i=1}^{m} \alpha_{i}=1$ and $0 \leq \alpha_{i} \leq 1$.

The main advantage of this formulation compared to other alternatives (i.e., additive or multiplicative-additive forms) is that Cobb-Douglas MAUF is coherent with neoclassic Economic Theory, since it meets Inada [53] conditions that guaranty there is a global optimum when the efficient frontier is convex, and this formulation is consistent with the postulate of decreasing marginal utility for every attribute (exponents $\alpha_{i}$ are lower than one). 
Using expressions (8)-(10) and (12), for any pair of attributes $i$ and $j$, the $M R S_{i, j}$ can be calculated as:

$M R S_{i, j}=-\frac{\frac{\partial U}{\partial u_{j}}}{\frac{\partial U}{\partial u_{i}}}=-\frac{\alpha_{j} \frac{U\left(u_{1}, \ldots, u_{m}\right)}{u_{j}}}{\alpha_{i} \frac{U\left(u_{1}, \ldots, u_{m}\right)}{u_{i}}}=-\frac{\alpha_{j} u_{i}}{\alpha_{i} u_{j}}=-\frac{w_{j}^{K}}{w_{i}{ }^{K}}=\beta_{i, j}^{K} \quad \forall i \neq j$

where $u_{i}$ is the value of $f_{i}$ in the equilibrium (efficient point $P^{K}$ ).

Considering the $m(m-1) / 2$ combinations of attributes $i$ and $j$ derived from (13), and the normalizing equation $\sum_{i=1}^{m} \alpha_{i}=1$, it is possible to calculate the values for $\alpha_{i}$ using expression (14), which allows us to elicit the parameters of a MAUF able to represent farmers' actual decision-making.

$\alpha_{i}=\frac{f_{i}^{K}}{f_{i}^{K}-\sum_{j=1}^{m} \beta_{i, j}^{K} \cdot f_{j}^{K}} \quad \forall i \neq j$

\section{Illustrative application}

The irrigated area of Sector BXII is located on the left-hand side of the river Guadalquivir, close to its mouth in the Atlantic Ocean in the Andalusia region of southern Spain. This irrigated area comprises 14,643 hectares (ha), divided into 499 farms (average farm size is $29.3 \mathrm{ha}$ ). The main crops are cotton, corn, tomatoes, sugar-beet, wheat, sunflower, carrots, and onions.

In order to collect primary data from farmers, an ad hoc survey was conducted, and a stratified sample method was adopted with respect to farm size, to determine a representative sample of farmers/farms. In each stratum, farmers were selected randomly, and a total of 60 farmers were interviewed face-to-face. Data gathered allows the description of individual farms (farm structure, crop-mix, agricultural practices, etc.) and their holders (socio-demographic profiles of farmers).

\subsection{Farmers’ heterogeneity}

A large number of studies have highlighted farmers' heterogeneity regarding their decisionmaking within the same agricultural system [42, 54, 55]. This heterogeneity was also found in the data collected in our survey, as several crop-mixes (i.e., farmers' decision-making) were identified. Provided an irrigated area offers the same production possibilities to all farmers, similar technological level, a proportional availability of resources, and similar profit expectations for each crop, differences in farmers' decision-making must be primarily due to differences in their objective functions (i.e., different individual MAUFs). Therefore the 
method proposed to elicit farmers' individual MAUF is suitable for analyzing heterogeneity in farmers’ decision-making, as shown in this case study.

Empirically implementing the PMAUP requires the application of this approach to each individual farmer sampled. However to facilitate clear reporting of the results, we have applied this method to a reduced number of representative farmers/farms. Cluster analysis was conducted to group farmers using the crop mixes of each farmer in 2014 (crop's share of total planted area) as classification variables. As a result, homogeneous groups or clusters of farmers/farms were identified according to variables that can be considered as proxies of their decision-making criteria.

Considering these homogeneous groups and the data collected in the survey, we identified three different farm-types (i.e., average farms of each cluster). A profile of each farm-type is assigned taking into account only statistically significant variables:

- Farm-type 1: "Large commercial farmers". This group of farmers represents 39\% of the farmers in the sample and $52 \%$ of the total area. They cultivate the largest farms in the irrigated area (35.8 ha on average) and farm mainly horticultural crops (around $40 \%$ of the farm area): tomatoes (28.3\%), carrots (7.7\%) and onions (2.5\%), which are the most profitable crops the farmers can choose. Other crops of importance are cotton (30.1\%) and sugar-beet (22.2\%).

- Farm-type 2: “Risk-diversification farmers". This group of farmers represents $41 \%$ of the farmers in the sample who farm $36 \%$ of the total irrigated area. They manage medium-size farms (23.9 ha on average), mostly growing cotton (58.1\%), tomatoes (12.0\%), corn (9.0\%), wheat (6.1\%), and sugar-beet (4.5\%). This variety of crops suggests farmers use crop diversification as a strategy to minimize their production risk.

- Farm-type 3: "Extensive farmers". This group of farmers represents the smallest proportion of farmers and irrigated area (20\% and $11 \%$ respectively). They cultivate the smallest farms (15.0 ha on average), growing extensive crops such as cotton (57.1\%), and sugar-beet (38.5\%), and are highly dependent on the European Common Agricultural Policy (CAP) subsidies.

Although the results for each farmer/farm sampled are also available, the sections 4.2 and 4.3 focus on the results obtained for these three farm-types as representative farm profiles of the agricultural system analyzed. 


\subsection{Model building}

Modeling farmers' behavior first requires the definition of crop-mix or decision variables $\left(\vec{x}_{c}=\left(x_{1}, \ldots, x_{c}, \ldots, x_{n}\right)\right)$. In this case decision variables are represented by the area devoted to each crop.

The questionnaire used for data gathering was designed to collect information about farm characteristics (e.g., size, hired workers, crop rotations), management of each crop (e.g., yields, subsidies, etc.), current farmers' decision-making (crops pattern adopted in 2014) and direct questions on criteria relevance (ranking of eight potential criteria), and socio-demographic data from the respondents. Data from the survey, alongside secondary data, allowed us to estimate the technical coefficients needed for model building, as shown in Table 2.

\section{Table 2}

Yield, Price, direct subsidy, variable production cost, gross margin and labor requirements for each crop

\begin{tabular}{lrrrrrr}
\hline Decision variable & $\begin{array}{r}\text { Yield } \\
(\mathrm{kg})\end{array}$ & $\begin{array}{r}\text { Price } \\
(\text { Euro/kg) }\end{array}$ & $\begin{array}{r}\text { CAP subsidy } \\
\text { (Euro/ha) }\end{array}$ & $\begin{array}{r}\text { Var. costs } \\
(\text { Euro/ha) }\end{array}$ & $\begin{array}{r}\text { Gross margin } \\
(\text { Euro/ha) }\end{array}$ & $\begin{array}{r}\text { Labor } \\
\text { (hours/ha) }\end{array}$ \\
\hline Wheat & 6,686 & 0.24 & --- & 608 & 992 & 8.3 \\
Corn & 14,824 & 0.23 & --- & 1,629 & 1,784 & 13.0 \\
Sugar-beet & 77,476 & 0.03 & 1,167 & 1,209 & 2,123 & 47.0 \\
Cotton & 3,536 & 0.53 & 1,314 & 1,386 & 1,789 & 14.6 \\
Sunflower & 3,457 & 0.45 & --- & 611 & 928 & 7.9 \\
Tomato & 118,533 & 0.07 & --- & 3,954 & 4,817 & 46.0 \\
Onion & 48,436 & 0.19 & --- & 3,497 & 5,792 & 29.5 \\
Carrot & 45,078 & 0.17 & --- & 3,398 & 4,351 & 24.5 \\
\hline
\end{tabular}

Responses from farmers on criteria importance demonstrated that $95 \%$ of the producers ranked higher expected profit, lower risk and lower management complexity as the most important management criteria. Similar evidence can be found in the literature [36, 46, 56, 57], and therefore, these are the potentially relevant attributes considered by farmers to be included in their MAUF.

The first attribute can be easily measured through the expected total gross margin (TGM). As a proxy of profit in the short-run, this attribute was calculated by multiplying the expected gross margin per crop and hectare (see Table 2) by the area cultivated with each crop $\left(x_{c}\right)$. Results are shown in 2014 constant euros. 
The attribute of risk was measured through the variance of the TGM (VAR). Risk was computed as $\vec{x}_{c}^{\prime}[\mathrm{Cov}] \vec{x}_{c}$, where [Cov] is the variance-covariance matrix of the crop gross margins per hectare obtained by using a time series of seven years (2007-2013).

Measuring management complexity is more difficult as several indicators can be used. For this case study total labor input (TL) was considered as the best proxy for managerial involvement, on the basis that labor-intensive crops require more technical supervision by the farmer [58]. This attribute was calculated by multiplying labor requirements per crop and hectare in hours (see Table 2) by the area cultivated with each crop $\left(x_{c}\right)$.

For operational purposes all attributes are normalized in order to: (i) be transformed into more-is-better objective functions and (ii) be bounded between 0 and 1. First, transforming lessis-better to more-is-better attributes has been done by multiplying the attribute by $(-1)$. Normalizing can be assessed by using different alternatives such as considering the observed value of the attribute $\left(\frac{f_{i}}{f_{i}^{\text {obs }}}\right)$ or the ideal point $\left(\frac{f_{i}}{f_{i}^{*}}\right)$ as reference points. In addition, some authors such as [59] suggested that a suitable range of performance for any attribute can be defined considering its best (ideal) and worst (anti-ideal) feasible values. Thus, a useful way for normalizing attributes measured in different scales is by considering the difference between the ideal and anti-ideal values as a reference point. In this paper, we decided to follow this last approach, identifying the ideal and anti-ideal values in the pay-off matrix (see Section 3 for details on the pay-off matrix calculation). Due to this selection, and in order to bound attributes between 0 and 1 , the anti-ideal value is also included in the numerator as a reference (see [37] for an application of this normalization process).

Following this last approach, the normalization of all attributes in the application of the PMAUP approach has been done by using the following expressions: $u_{i}=\frac{f_{i}\left(\vec{x}_{c}\right)-f_{i_{*}}}{f_{i}{ }^{*}-f_{i_{*}}}$ for moreis-better attributes, and $u_{i}=\frac{f_{i_{*}}-f_{i}\left(\vec{x}_{c}\right)}{f_{i_{*}}-f_{i}{ }^{*}}$ for less-is-better attributes ${ }^{9}$. As a result all attributes become an objective to be maximized (i.e. for less-is-better attributes ' $\mathrm{f}_{\mathrm{i}}^{\prime}, \mathrm{u}_{\mathrm{i}}$ can be interpreted as 'avoided $\mathrm{f}_{\mathrm{i}}$ '), and vary between 0 and 1 , being 1 the ideal point and 0 the anti-ideal point ${ }^{10}$.

\footnotetext{
${ }^{9}$ Different normalization procedures may result in slightly differences in the simulation process, but the validity of the method does not depend on this choice.

${ }^{10}$ The normalization method uses ideal and anti-ideal points as a reference, as the multicriterion TOPSIS method does (see [60-64] for recent applications of the TOPSIS method). In this sense, both approaches are similar, since the closest the value to $1(0)$ the closest the alternative or point to the ideal (anti-ideal) point. However, the purpose
} 
Thus, the attributes have been transformed into normalized objective functions as follows:

$u_{T G M}=\frac{T G M\left(\vec{x}_{c}\right)-T G M_{*}}{T G M^{*}-T G M_{*}} ; u_{V A R}=\frac{V A R_{*}-V A R\left(\vec{x}_{c}\right)}{V A R_{*}-V A R^{*}} ; u_{T L}=\frac{T L_{*}-T L\left(\vec{x}_{c}\right)}{T L_{*}-T L^{*}}$

where $T G M^{*}\left(T G M_{*}\right), V A R^{*}\left(V A R_{*}\right)$ and $T L^{*}\left(T L_{*}\right)$ are the ideal (anti-ideal) values for each attribute in the pay-off matrix. As commented above, using this approach $u_{V A R}$ can be considered as 'avoided risk', and $u_{T L}$ as 'avoided complexity management'.

Including these single-attribute functions, farmers' behavior can be reasonably explained by the maximization of the following homothetic Cobb-Douglas MAUF:

$U\left(u_{T G M}, u_{V A R}, u_{T L}\right)=u_{T G M}{ }^{\alpha_{1}} \cdot u_{V A R}{ }^{\alpha_{2}} \cdot u_{T L}^{\alpha_{3}}$

where $\alpha_{i}$ are the parameters associated to each single-attribute function, which are normalized to add up to one.

Finally, the following constraints $\left(A \vec{x}_{c} \leq B\right.$ in expression (1)) have been included in the construction of the models:

a) Land constraint. The sum of the area farmed with each crop $\left(x_{c}\right)$ must be equal to the total area available for each farm/farm-type $\left(S_{t}\right)$.

b) Water constraint. Total irrigation water requirements $\left(W R_{t}\right)$ must be lower than or equal to total water allotment to each farm-type $\left(W A_{t}\right)$. The total irrigation water requirements in each farm-type is $W R_{t}=\sum_{c=1}^{n} w r_{c} \cdot x_{c}$, being $w r_{c}$ the water requirement per crop and hectare.

c) Sugar-beet quota. Due to production quotas established by the CAP, the share of the farm cultivated with sugar-beet was constrained to the maximum area in the period studied in each farm-type.

d) Rotational and agronomic constraints. These restrictions were included in the model according to the criteria revealed by the farmers in the survey.

e) Market constraints. Some crops are subject to marketing channels due to the fact that they cannot be stored for extended periods (perishable products). This implies that it is unlikely that farmers would modify significantly the area cultivated with such crops due to the inability of the market to absorb great variations in the short-run. This is the case for tomatoes, onions, and carrots. In order to model this constraint, an upper limit of the area cultivated with these crops was included on the basis of the maximum historical cultivation during the previous seven years.

of both methods are rather different, and while TOPSIS aims at evaluating and ranking a discrete set of alternatives, the normalization approach aims at assessing a continuous space of alternatives (i.e., crop-mixes). 
f) In addition to the previous constraints, we assume that the decision variables $\left(\vec{x}_{c}\right)$ must be greater or equal to zero.

Once the main elements of the model (i.e., decision variables, objective function and constraints) are properly defined, the first step is to obtain the pay-off matrix for each farm/farm-type by individually maximizing each of the three attributes included in the farmers' MAUF $\left(u_{T G M}, u_{V A R}\right.$ and $\left.u_{T L}\right)$. These matrices evidence the conflict existing among the various criteria, and how observed values for each attribute in each farm are within the ranges defined by the ideal and anti-ideal values (see Table 3).

\section{Table 3}

Pay-off matrix of each farm-type

\begin{tabular}{|c|c|c|c|c|}
\hline & & $\begin{array}{r}T G M \\
\text { (euros) }\end{array}$ & $\begin{array}{r}V A R \\
\left(10^{4} \text { euros }^{2}\right)\end{array}$ & $\begin{array}{r}T L \\
\text { (hours) }\end{array}$ \\
\hline \multirow{4}{*}{$\begin{array}{l}\text { Farm-type } 1 \\
\left(S_{1}=35.8 \mathrm{ha}\right)\end{array}$} & $\operatorname{Max} u_{T G M}\left(\vec{x}_{c}\right)$ s.t. $A \vec{x}_{c} \leq B$ & $111,228^{*}$ & $32,663 *$ & $1,211_{*}$ \\
\hline & $\operatorname{Max} u_{V A R}\left(\vec{x}_{c}\right)$ s.t. $A \vec{x}_{c} \leq B$ & 83,035 & $1,590^{*}$ & 917 \\
\hline & $\operatorname{Max} u_{T L}\left(\vec{x}_{c}\right) \quad$ s.t. $A \vec{x}_{c} \leq B$ & $49,715_{*}$ & 23,741 & $389^{*}$ \\
\hline & Observed (year 2014) & 105.647 & 25.108 & 1.159 \\
\hline \multirow{4}{*}{$\begin{array}{l}\text { Farm-type } 2 \\
\left(S_{2}=23.9 \mathrm{ha}\right)\end{array}$} & $\operatorname{Max} u_{T G M}\left(\vec{x}_{c}\right)$ s.t. $A \vec{x}_{c} \leq B$ & $55,911^{*}$ & $5,838 *$ & $517 *$ \\
\hline & $\operatorname{Max} u_{V A R}\left(\vec{x}_{c}\right)$ s.t. $A \vec{x}_{c} \leq B$ & 37,609 & $834^{*}$ & 356 \\
\hline & $\operatorname{Max} u_{T L}\left(\vec{x}_{c}\right) \quad$ s.t. $A \vec{x}_{c} \leq B$ & $22,985 *$ & 5,756 & $194^{*}$ \\
\hline & Observed (year 2014) & 53,051 & 3,047 & 489 \\
\hline \multirow{4}{*}{$\begin{array}{l}\text { Farm-type } 3 \\
\left(S_{3}=15.0 \mathrm{ha}\right)\end{array}$} & $\operatorname{Max} u_{T G M}\left(\vec{x}_{c}\right)$ s.t. $A \vec{x}_{c} \leq B$ & $27,348^{*}$ & 824 & 428 \\
\hline & $\operatorname{Max} u_{V A R}\left(\vec{x}_{c}\right)$ s.t. $A \vec{x}_{c} \leq B$ & 24,731 & $634^{*}$ & $371 *$ \\
\hline & $\operatorname{Max} u_{T L}\left(\vec{x}_{c}\right) \quad$ s.t. $A \vec{x}_{c} \leq B$ & $19,421 *$ & $1,469 *$ & $172^{*}$ \\
\hline & Observed (year 2014) & 26,683 & 797 & 405 \\
\hline
\end{tabular}

Note: $\left({ }^{*}\right)$ shows ideal values and (*) shows anti-ideal values.

\subsection{Results}

Implementing the PMAUP approach, (4) to (10), implies that the weights of each attribute $\left(\vec{w}^{k}\right)$ are obtained successively in each iteration $(k)$ for each farmer's profile (farm-types 1 to 3), as can be seen in Table 4. It can be observed that weights converge rather quickly. In fact, if $\delta$ in expression (11) is fixed at 0.0001 , actual weights are obtained in less than seven iterations. 


\section{Table 4}

Attributes, weights and MRT/MRS obtained for each attribute $i$ in each iteration $k$

\begin{tabular}{|c|c|c|c|c|c|c|c|c|c|c|c|}
\hline & & & \multicolumn{3}{|c|}{ Attributes } & \multicolumn{3}{|c|}{ Weights } & \multicolumn{3}{|c|}{$\begin{array}{l}\text { Marginal Rate of Transformation }\left(\beta_{i, j}^{k}\right)= \\
\quad=\text { Marginal Rate of Substitution }\end{array}$} \\
\hline & & & $\begin{array}{l}\text { Total Gross } \\
\text { Margin } \\
\text { (Euro) }\end{array}$ & $\begin{array}{c}\text { Variance } \\
\left(10^{4} \text { Euro }^{2}\right)\end{array}$ & $\begin{array}{l}\text { Total Labor } \\
\text { Input } \\
\text { (hours) }\end{array}$ & $w_{u_{T G M}}$ & $w_{u_{V A R}}$ & $w_{u_{T L}}$ & $\beta_{G M, R I S K}$ & $\beta_{\text {RISK }, L A B O U R}$ & $\beta_{L A B O U R, G M}$ \\
\hline \multirow{5}{*}{ Farm-type 1} & \multirow{4}{*}{$\begin{array}{l}\text { Iteration } \\
\text { number } \\
\quad(k)\end{array}$} & $k=1$ & 106,224 & 22,673 & 1,079 & 0.33333 & 0.33333 & 0.33333 & -0.2304 & -0.6849 & -6.3375 \\
\hline & & $k=2$ & 107,166 & 23,633 & 1,126 & 0.72038 & 0.16595 & 0.11367 & -0.2305 & -0.5653 & -7.6746 \\
\hline & & $k=5$ & 107,203 & 23,589 & 1,132 & 0.73650 & 0.17061 & 0.09289 & -0.2317 & -0.5440 & -7.9343 \\
\hline & & $k=6$ & 107,203 & 23,589 & 1,132 & 0.73653 & 0.17064 & 0.09283 & -0.2317 & -0.5440 & -7.9351 \\
\hline & \multicolumn{2}{|c|}{ Observed (year 2014) } & 105,647 & 25,108 & 1,159 & & & & & & \\
\hline \multirow{2}{*}{ Farm-type 2} & $\begin{array}{l}\text { Iteration } \\
\text { number } \\
(k)\end{array}$ & $k=1$ & 53,349 & 2,733 & 458 & 0.33333 & 0.33333 & 0.33333 & -1.7476 & -0.4184 & -1.3676 \\
\hline & \multicolumn{2}{|c|}{ Observed (year 2014) } & 53,051 & 2,964 & 489 & & & & & & \\
\hline \multirow{4}{*}{ Farm-type 3} & \multirow{3}{*}{$\begin{array}{l}\text { Iteration } \\
\text { number } \\
\quad(k)\end{array}$} & $k=1$ & 26,682 & 796 & 405 & 0.33333 & 0.33333 & 0.33333 & -1.1532 & -0.3353 & -2.5864 \\
\hline & & $k=2$ & 26,682 & 796 & 405 & 0.45404 & 0.15223 & 0.39373 & -1.1532 & -0.3353 & -2.5864 \\
\hline & & $k=3$ & 26,682 & 796 & 405 & 0.45404 & 0.15223 & 0.39373 & -1.1532 & -0.3353 & -2.5864 \\
\hline & \multicolumn{2}{|c|}{ Observed (year 2014) } & 26,682 & 796 & 405 & & & & & & \\
\hline
\end{tabular}


Weights of single-attribute utility functions show different behavior among the groups defined by the cluster analysis, confirming the need to define a different MAUF for each group. In addition, these weights support the profile assigned to each farm-type on the basis of the observed crop-mixes. Decision-making in Farm-type 1 is mainly led by profit maximization $\left(w_{u_{T G M}}=73.7 \%\right)$, although avoiding risk and management complexity are also taken into account $\left(w_{u_{V A R}}=17.1 \%\right.$ and $\left.w_{u_{T L}}=9.3 \%\right)$. Despite profit maximization is the main objective for Farm-type $2\left(w_{u_{T G M}}=50.4 \%\right)$, the attributes related to risk and management complexity are more relevant $\left(w_{u_{V A R}}=20.8 \%\right.$ and $\left.w_{u_{T L}}=28.8 \%\right)$ in its decision-making than for Farm-type 1 . Finally, Farm-type 3 is driven by both profit maximization and minimizing management complexity $\left(w_{u_{T G M}}=45.4 \%\right.$ and $\left.w_{u_{T L}}=39.4 \%\right)$.

Once the weights have converged, including $w_{i}^{K}$ in the problem (4) allowed us to obtain the efficient solution $P^{K}$, that might also be achieved by solving model (1) considering an adequate MAUF. As previously mentioned, the MAUF that represents famers' behavior can be reasonably assumed to have a homothetic Cobb-Douglas specification (12), whose $\alpha_{i}$ parameters can be obtained by solving the expression (14). Following this approach we obtained the MAUFs for each farm-type:

$$
\begin{aligned}
& U_{1}=u_{T G M}{ }^{0.9215} \cdot u_{V A R}{ }^{0.0667} \cdot u_{T L}{ }^{0.0118} \\
& U_{2}=u_{T G M}{ }^{0.7284} \cdot u_{V A R}{ }^{0.1912} \cdot u_{T L}^{0.0804} \\
& U_{3}=u_{T G M}{ }^{0.7254} \cdot u_{V A R}{ }^{0.2137} \cdot u_{T L}^{0.0609}
\end{aligned}
$$

Differences in these MAUFs show different farmer-type decision-making [42].

Finally, in order to test the capacity of the model to reproduce farmers' behavior, it is worth analyzing the differences between the observed behavior and the estimated results provided by the PMAUP approach (Table 5). The Percentage Absolute Deviation (PAD) and the FingerKreinin similarity index (FK, see [65]) have been calculated to show the differences in cropmixes:

$P A D$ index $(\%)=\frac{\sum_{c=1}^{n}\left|x_{c}^{o b s}-x_{c}^{P M A U P}\right|}{\sum_{c=1}^{n} x_{c}^{o b s}}$

$F K$ similarity index $=\sum_{c=1}^{n} \min \left(\frac{x_{c}^{\text {PMAUP }}}{s_{t}} ; \frac{x_{c}^{o b s}}{s_{t}}\right)$

PAD compares calibrated $\left(x_{c}^{P M A U P}\right)$ and observed $\left(x_{c}^{o b s}\right)$ crop areas by adding all absolute deviations and is expressed as a percentage. Thus, this index varies form $0 \%$ (perfect calibration 
fitting) to $200 \%$ (the worst possible calibration). The FK index compares the calibrated $\left(\frac{x_{c}^{P M A U P}}{s_{t}}\right)$ and the observed $\left(\frac{x_{c}^{o b s}}{s_{t}}\right)$ shares of each crop-mix, varying between $0 \%$ and $100 \%$, with the latter being an exact match between observed and simulated crop-mixes.

PAD ranges from $0.0 \%$ (Farm-type 3) to 33.2\% (Farm-type 2), while FK index fluctuates from 100.0\% (Farm-type 3) to 83.4\% (Farm-type 2). Although there is no limit or threshold values for both indexes to validate this methodological approach, the results show that estimated and actual crop-mixes are quite similar for each cluster. Similar results were obtained for individual farms simulation. In conclusion, the PMAUP is able to provide a reliable approach to modeling farmers' decision processes.

\section{Table 5}

Simulated and observed crop-mix for each farm-type (hectares)

\begin{tabular}{lcccccc}
\hline & \multicolumn{2}{c}{ Farm-type 1 } & \multicolumn{2}{c}{ Farm-type 2 } & \multicolumn{2}{c}{ Farm-type 3 } \\
\cline { 2 - 7 } Crop-mix & $\begin{array}{r}\text { PMAUP } \\
\text { estimation }\end{array}$ & Observed & $\begin{array}{r}\text { PMAUP } \\
\text { estimation }\end{array}$ & Observed & $\begin{array}{r}\text { PMAUP } \\
\text { estimation }\end{array}$ & Observed \\
\hline Wheat & 0.00 & 1.94 & 0.00 & 1.58 & 0.59 & 0.59 \\
Corn & 2.09 & 1.17 & 6.20 & 2.30 & --- & --- \\
Sugar-beet & 7.50 & 8.65 & 0.67 & 1.54 & 5.86 & 5.86 \\
Cotton & 12.68 & 10.64 & 12.89 & 14.21 & 8.55 & 8.55 \\
Sunflower & --- & --- & 0.53 & 0.51 & --- & --- \\
Tomato & 10.81 & 10.91 & 2.97 & 3.17 & --- & --- \\
Onion & 0.65 & 0.59 & 0.15 & 0.14 & --- & --- \\
Carrot & 2.09 & 1.90 & 0.54 & 0.49 & --- & --- \\
\hline \multicolumn{1}{c}{ Total (ha) } & 35.80 & 35.80 & 23.95 & 23.95 & 15.00 & 15.00 \\
\hline \multicolumn{1}{c}{ PAD index } & \multicolumn{2}{c}{$17.9 \%$} & & $33.2 \%$ & & $0.0 \%$ \\
\hline \multicolumn{1}{c}{ FK index } & \multicolumn{2}{c}{$91.1 \%$} & $83.4 \%$ & \multicolumn{2}{c}{$100.0 \%$} \\
\hline
\end{tabular}

Similarly, the accuracy of the PMAUP can be tested by comparing the differences between observed and simulated results for attributes. As shown in Table 6, all deviations are below $6.2 \%$, suggesting an accurate approximation of farmers' actual decision-making. The analysis conducted at individual farm level also confirms the model's ability to accurately reproduce farmers' decision-making. 


\section{Table 6}

Simulated and observed values of attributes for each farm-type

\begin{tabular}{|c|c|c|c|c|}
\hline & & \multicolumn{3}{|c|}{ Attributes } \\
\hline & & Total Gross & Variance & Total Labor \\
\hline & & Margin (Euro) & $\left(10^{4}\right.$ Euro $\left.^{2}\right)$ & Input (hours) \\
\hline \multirow{3}{*}{ Farm-type 1} & PMAUP estimation & 107,203 & 23,589 & 1,132 \\
\hline & Observed (year 2014) & 105,647 & 25,108 & 1,159 \\
\hline & Divergence & $-1.5 \%$ & $+6.1 \%$ & $+2.3 \%$ \\
\hline \multirow{3}{*}{ Farm-type 2} & PMAUP estimation & 53,564 & 2,800 & 459 \\
\hline & Observed (year 2014) & 53,051 & 2,964 & 489 \\
\hline & Divergence & $-1.0 \%$ & $+5.5 \%$ & $+6.2 \%$ \\
\hline \multirow{3}{*}{ Farm-type 3} & PMAUP estimation & 26,683 & 797 & 405 \\
\hline & Observed (year 2014) & 26,683 & 797 & 405 \\
\hline & Divergence & $0.0 \%$ & $0.0 \%$ & $0.0 \%$ \\
\hline
\end{tabular}

\section{Concluding remarks}

In this article we offer a new mathematical programming model to simulate farmers' decision-making on the basis of a positive multi-attribute approach. Evidence shows that expected profitability (or its higher moments) is not the only criterion considered by farmers in their decision-making. Invoking the multi-attribute decision-making paradigm, the positive multi-attribute utility programming (PMAUP) proposed allows us to overcome the limitations of positive mathematical approaches found in the literature by including other criteria that are relevant to farmers' decision-making. The PMAUP also addresses some weaknesses of previous multi-attribute approaches used to simulate farmers' behavior, such as the assessment of the efficient set and the elicitation of the multi-attribute utility function (MAUF).

Following a five-step procedure, the PMAUP allows us to assess the actual efficient set and the parameters of the MAUF as consistent with the observed farmer's behavior (both decision variables -crop-mix- and the attributes considered), in the sense that this observed decisionmaking is 'close' enough to the optimal results obtained maximizing the elicited MAUF. Through an iterative process, the PMAUP also allows the estimation of the importance (weights) given by farmers to each attribute included in the MAUF. Our results corroborate previous studies with respect to heterogeneous behaviors of agricultural producers within 
homogeneous agricultural systems. This heterogeneity can be assessed by using different MAUFs as surrogates of farmers' behavior.

The potential of the PMAUP model to replicate farmers' decision-making has been proven by applying it to a sample of irrigated farms in southern Spain. In order to present the results, a cluster analysis was conducted to group farmers into homogeneous groups according to their crop-mix, as a proxy of their decision-making criteria. Results show that the PMAUP provides an accurate simulation of farmers' observed decisions, with dissimilarities that range between $0 \%$ and $17 \%$ for crop-mixes, and below $6.3 \%$ for attributes. Thus, we can conclude that the lower the number of crops the higher the accuracy of the PMAUP model in replicating farmers' decision-making.

This new approach not only allows accurate simulations of observed decisions but enables to conduct proper simulations of the response of individual farmers (or farmer typology) when facing hypothetical scenarios (policy reforms, market shocks, etc.), providing further insights into their current heterogeneous behavior and their feasible response to these changes. In any case further empirical research on the PMAUP method is needed to compare its simulation goodness-of-fit when compare to other alternative approaches (e.g., PMP, EUT and other alternative approaches aiming at a positive elicitation of the decision-makers' MAUF). Therefore, comparing ex-ante analysis of policy measures (e.g., reform of agricultural policies) by different modeling approaches could be of interest in order to compare their power to model.

From the methodological point of view, further work is also needed to analyze how different distance measures may have an influence on projections (e.g. testing whether metrics different to the Euclidean distance yields better fitting), or test the performance of other MAUF functional forms. This future research may provide further insights on farmers' behavior, leading to more accurate simulation procedures.

\section{Acknowledgements}

The authors acknowledge the financial support from the Spanish Ministry of Economics and Competitiveness (MINECO) and the European Regional Development Fund (ERDF) through the research project MERCAGUA (AGL2013-48080-C2-1-R). These funding institutions had no involvement in the conduction of the research nor the preparation of the article. 


\section{References}

[1] Buysse J, Fernagut B, Harmignie O, de Frahan BH, Lauwers L, Polomé P, et al. Farm-based modelling of the EU sugar reform: Impact on Belgian sugar beet suppliers. Eur Rev Agr Econ. 2007;34:21-52. doi:10.1093/erae/jbm001

[2] Janssen S, van Ittersum MK. Assessing farm innovations and responses to policies: A review of bioeconomic farm models. Agr Syst. 2007;94:622-36. doi:10.1016/j.agsy.2007.03.001

[3] von Neumann J, Morgenstern O. Theory of games and economic behavior. Princeton: Princeton University Press; 1944.

[4] Chavas J-P, Chambers RG, Pope RD. Production economics and farm management: A century of contributions. Am J Agr Econ. 2010;92:356-75. doi:10.1093/ajae/aaq004

[5] Starmer C. Developments in non-expected utility theory: The hunt for a descriptive theory of choice under risk. J Econ Lit. 2000;38:332-82. doi:10.1257/jel.38.2.332

[6] Bocquého G, Jacquet F, Reynaud A. Expected Etility or Prospect Theory maximisers? Assessing farmers' risk behaviour from field-experiment data. Eur Rev Agr Econ. 2014;41:135-72. doi:10.1093/erae/jbt006

[7] Just DR, Peterson HH. Is Expected Utility Theory applicable? A revealed preference test. Am J Agr Econ. 2010;92:16-27. doi:10.1093/ajae/aap015

[8] Howitt RE. Positive Mathematical Programming. Am J Agr Econ. 1995;77:329-42. doi:10.2307/1243543

[9] Henry de Frahan B, Buysse J, Polomé P, Fernagut B, Harmignie O, Lauwers L, et al. Positive Mathematical Programming for agricultural and environmental policy analysis: Review and practice. In: Weintraub A, Romero C, Bjørndal T, Epstein R, Miranda J, editors. Handbook of Operations Research in Natural Resources. New York: Springer; 2007. p. 129-54. doi:10.1007/9780-387-71815-6_8

[10] Cortignani R, Severini S. Modelling farmer participation to a revenue insurance scheme by the means of the Positive Mathematical Programming. Agric Econ - Czech. 2012;58:324-31.

[11] Petsakos A, Rozakis S. Calibration of agricultural risk programming models. Eur J Oper Res. 2015;242:536-45. doi:10.1016/j.ejor.2014.10.018

[12] Nakashima T. Positive Mathematical Programming for farm planning: Review. Jpn Agr Res Q. 2011;45:251-8. doi:10.6090/jarq.45.251

[13] Heckelei T, Britz W, Zhang Y. Positive Mathematical Programming approaches-recent developments in literature and applied modelling. Bio-based Appl Econ. 2012;1:109-24. doi:10.13128/BAE-10567

[14] Harman WL, Eidman VR, Hatch RE, Claypool PL. Relating farm and operator characteristics to multiple goals. South J Agr Econ. 1972;4:215-20. doi:10.1017/S0081305200010669 
[15] Gasson R. Goals and values of farmers. J Agr Econ. 1973;24:521-42. doi:10.1111/j.14779552.1973.tb00952.x

[16] Smith D, Capstick DF. Establishing priorities among multiple management goals. South J Agr Econ. 1976;2:37-43. doi:10.1017/S0081305200013212

[17] Harper WM, Eastman C. An evaluation of goal hierarchies for small farm operators. Am J Agr Econ. 1980;62:742-7. doi:10.2307/1239774

[18] Kliebenstein JB, Barrett DA, Hefferman WD, Kirtley CL. An analysis of farmers' perceptions of benefit received from farming. N Cent J Agr Econ. 1980;2:131-6. doi:10.2307/1349176

[19] Basarir A, Gillespie JM. Multidimensional goals of beef and dairy producers: An inter-industry comparison. Agr Econ. 2006;35:103-14. doi:10.1111/j.1574-0862.2006.00143.x

[20] Solano C, León H, Pérez E, Tole L, Fawcett RH, Herrero M. Using farmer decision-making profiles and managerial capacity as predictors of farm management and performance in Costa Rican dairy farms. Agr Syst. 2006;88:395-428. doi:10.1016/j.agsy.2005.07.003

[21] Berkhout ED, Schipper RA, Kuyvenhoven A, Coulibaly O. Does heterogeneity in goals and preferences affect efficiency? A case study of farm households in northern Nigeria. Agr Econ. 2010;41:265-73. doi:10.1111/j.1574-0862.2010.00449.x

[22] Kallas Z, Serra T, Gil JM. Farmers' objectives as determinants of organic farming adoption: The case of Catalonian vineyard production. Agr Econ. 2010;41:409-23. doi:10.1111/j.15740862.2010.00454.x

[23] Mandryk M, Reidsma P, Kanellopoulos A, Groot JCJ, van Ittersum MK. The role of farmers' objectives in current farm practices and adaptation preferences: A case study in Flevoland, the Netherlands. Reg Environ Change. 2014;14:1463-78. doi:10.1007/s10113-014-0589-9

[24] Ajzen I. The Theory of Planned Behavior. Organ Behav Hum Dec. 1991;50:179-211. doi:10.1016/0749-5978(91)90020-T

[25] Borges JAR, Foletto L, Xavier VT. An interdisciplinary framework to study farmers decisions on adoption of innovation: Insights from Expected Utility Theory and Theory of Planned Behavior. Afr J Agr Res. 2015;10:2814-25. doi:10.5897/AJAR2015.9650

[26] Lynne GD. Modifying the neo-classical approach to technology adoption with behavioral science models. J Agr Appl Econ. 1995;27:67-80. doi:10.1017/S107407080001960X

[27] Bergevoet RHM, Ondersteijn CJM, Saatkamp HW, van Woerkum CMJ, Huirne RBM. Entrepreneurial behaviour of dutch dairy farmers under a milk quota system: Goals, objectives and attitudes. Agr Syst. 2004;80:1-21. doi:10.1016/j.agsy.2003.05.001

[28] Poppenborg P, Koellner T. Do attitudes toward ecosystem services determine agricultural land use practices? An analysis of farmers’ decision-making in a South Korean watershed. Land Use Policy. 2013;31:422-9. doi:10.1016/j.landusep

[29] Läpple D, Kelley H. Understanding the uptake of organic farming: Accounting for heterogeneities among Irish farmers. Ecol Econ. 2013;88:11-9. doi:10.1016/j.ecolecon.2012.12.025 
[30] Gocsik E, Saatkamp HW, de Lauwere CC, Lansink AO. A conceptual approach for a quantitative economic analysis of farmers' decision-making regarding animal welfare. J Agric Environ Ethics. 2014;27:287-308. doi:10.1007/s10806-013-9464-9

[31] Ajzen I, Fishbein M. Attitudes and the attitude-behavior relation: Reasoned and automatic processes. Eur Rev Soc Psychol. 2000;11:1-33. doi:10.1080/14792779943000116

[32] Willock J, Deary IJ, Edwards-Jones G, Gibson GJ, McGregor MJ, Sutherland A, et al. The role of attitudes and objectives in farmer decision making: Business and environmentally-oriented behaviour in Scotland. J Agr Econ. 1999;50:286-303. doi:10.1111/j.1477-9552.1999.tb00814.x

[33] Keeney RL, Raiffa H. Decisions with multiple objectives: Preferences and value trade-offs. New York: John Wiley \& Sons; 1976.

[34] Ballestero E, Romero C. Multiple criteria decision making and its applications to economic problems. New York: Springer; 1998. doi:10.1007/978-1-4757-2827-9

[35] Sumpsi JM, Amador F, Romero C. On farmers’ objectives: A multi-criteria approach. Eur J Oper Res. 1996;96:64-71. doi:10.1016/0377-2217(95)00338-X

[36] Amador F, Sumpsi JM, Romero C. A non-interactive methodology to assess farmers' utility functions: An application to large farms in Andalusia, Spain. Eur Rev Agr Econ. 1998;25:92-102. doi:10.1093/erae/25.1.92

[37] André FJ, Riesgo L. A non-interactive elicitation method for non-linear multiattribute utility functions: Theory and application to agricultural economics. Eur J Oper Res. 2007;181:793-807. doi:10.1016/j.ejor.2006.06.020

[38] André FJ, Herrero I, Riesgo L. A modified DEA model to estimate the importance of objectives with an application to agricultural economics. Omega. 2010;38:371-82. doi:10.1016/j.omega.2009.10.002

[39] André FJ. Indirect elicitation of non-linear multi-attribute utility functions. A dual procedure combined with DEA. Omega. 2009;37:883-95. doi:10.1016/j.omega.2008.06.002

[40] Romero C, Rehman T. Multiple criteria analysis for agricultural decisions. Amsterdam: Elsevier; 2003. doi:10.1016/S0926-5589(03)80002-X

[41] Ballestero E, Romero C. Utility optimization when the utility function is virtually unknown. Theor Decis. 1994;37:233-43. doi:10.1007/BF01079267

[42] Gómez-Limón JA, Riesgo L. Irrigation water pricing: Differential impacts on irrigated farms. Agr Econ. 2004;31:47-66. doi:10.1111/j.1574-0862.2004.tb00221.x

[43] van Calker KJ, Berentsen PBM, Romero C, Giesen GWJ, Huirne RBM. Development and application of a multi-attribute sustainability function for Dutch dairy farming systems. Ecol Econ. 2006;57:640-58. doi:10.1016/j.ecolecon.2005.05.016

[44] Bartolini F, Bazzani GM, Gallerani V, Raggi M, Viaggi D. The impact of water and agriculture policy scenarios on irrigated farming systems in Italy: An analysis based on farm level multiattribute linear programming models. Agr Syst. 2007;93:90-114. doi:10.1016/j.agsy.2006.04.006 
[45] Huirne RBM, Hardaker JB. A multi-attribute utility model to optimise sow replacement decisions. Eur Rev Agr Econ. 1998;25:488-505. doi:10.1093/erae/25.4.488

[46] Gutiérrez-Martín C, Gómez-Gómez CM. Assessing irrigation efficiency improvements by using a preference revelation model. Span J Agr Res. 2011;9:1009-20. doi:10.5424/sjar/20110904-514-10

[47] Hardaker JB, Huirne RBM, Anderson JR, Lien G. Coping with risk in agriculture. Wallingford (UK): CABI publishing; 2004. doi:10.1079/9780851998312.0000

[48] Ehrgott M. Multicriteria optimization. Heidelberg (Germany): Springer; 2005. doi:10.1007/3-54027659-9

[49] Gravelle H, Rees R. Microeconomics, 3rd ed. Harlow (UK): Prentice Hall-Financial Times; 2004.

[50] Varian HR. Intermediate microeconomics with calculus, 9th ed. New York: W.W. Norton \& co; 2014.

[51] Cobb CW, Douglas PH. A theory of production. Am Econ Rev. 1928;18:139-65.

[52] Sampson SE. Axiomatic justification for a geometric quality aggregation function. Decision Sci. 1999;30:415-40. doi:10.1111/j.1540-5915.1999.tb01616.x

[53] Inada K-I. On a two-sector model of economic growth: Comments and a generalization. Rev Econ Stud. 1963;30:119-27. doi:10.2307/2295809

[54] Pennings JME, Leuthold RM. The role of farmers' behavioral attitudes and heterogeneity in futures contracts usage. Am J Agr Econ. 2000;82:908-19. doi:10.1111/0002-9092.00090

[55] Berkhout ED, Schipper RA, van Keulen H, Coulibaly O. Heterogeneity in farmers' production decisions and its impact on soil nutrient use: Results and implications from northern Nigeria. Agr Syst. 2011;104:63-74. doi:10.1016/j.agsy.2010.09.006

[56] Gómez-Limón JA, Berbel J. Multicriteria analysis of derived water demand functions: A Spanish case study. Agr Syst. 2000;63:49-72. doi:10.1016/s0308-521x(99)00075-x

[57] Gómez-Limón JA, Riesgo L, Arriaza M. Multi-criteria analysis of input use in agriculture. J Agr Econ. 2004;55:541-64. doi:10.1111/j.1477-9552.2004.tb00114.x

[58] Kingwell R. Managing complexity in modern farming. Aust J Agr Resour Econ. 2011;55:12-34. doi:10.1111/j.1467-8489.2010.00528.x

[59] Salo AA, Hämäläinen RP. On the measurement of preferences in the Analytic Hierarchy Process. Journal of Multi-Criteria Decision Analysis. 1997;6:309-19. doi:10.1002/(SICI)10991360(199711)6:6<309::AID-MCDA163>3.0.CO;2-2

[60] Gallego-Ayala J. Selecting irrigation water pricing alternatives using a multi-methodological approach. Mathematical and Computer Modelling. 2012;55:861-83. doi:10.1016/j.mcm.2011.09.014

[61] Bilbao-Terol A, Arenas-Parra M, Cañal-Fernández V, Antomil-Ibias J. Using TOPSIS for assessing the sustainability of government bond funds. Omega. 2014;49:1-17. doi:10.1016/j.omega.2014.04.005 
[62] Kannan D, Jabbour ABLdS, Jabbour CJC. Selecting green suppliers based on GSCM practices: Using fuzzy TOPSIS applied to a Brazilian electronics company. Eur J Oper Res. 2014;233:43247. doi:10.1016/j.ejor.2013.07.023

[63] Mulliner E, Malys N, Maliene V. Comparative analysis of MCDM methods for the assessment of sustainable housing affordability. Omega. 2016. doi:10.1016/j.omega.2015.05.013

[64] Riesgo L, Gallego-Ayala J. Multicriteria analysis of olive farms sustainability: An application of TOPSIS models. In: Plà-Aragonés LM, editor. Handbook of Operations Research in Agriculture and the Agri-Food Industry: Springer New York; 2015. p. 327-53. doi:10.1007/978-1-4939-24837_15

[65] Finger JM, Kreinin ME. A measure of 'export similarity' and its possible uses. Econ J. 1979;89:905-12. doi:10.2307/2231506 